\title{
Custo de produção e análise de rentabilidade da pecuária leiteira em agricultura familiar $^{1}$
}

\author{
José Eustáquio Teixeira ${ }^{2}$, Marcos Aurélio Lopes ${ }^{3}$, Nádia Campos Pereira Bruhn ${ }^{4}$, Gercílio \\ Alves de Almeida Júnior ${ }^{5}$
}

\begin{abstract}
Resumo: A agricultura familiar apresenta relevante contribuição econômica e social no Brasil, onde está presente na maioria dos estabelecimentos rurais. No Estado de Minas Gerais há predominância de pequenos produtores de leite, principalmente em agricultura familiar e nesse contexto, objetivou-se identificar os principais componentes do custo de produção e analisar a rentabilidade em uma propriedade de pecuária leiteira em agricultura familiar nesse Estado. Os dados foram coletados durante um período de 12 meses, entre janeiro a dezembro de 2015, em um sistema de produção de leite localizado no município de Conceição da Barra de Minas. O processamento eletrônico dos dados e a análise de rentabilidade consideraram as margens bruta e líquida e o resultado como indicadores de eficiência econômica. As receitas superaram os custos operacionais e variáveis, no entanto, não foram suficientes para remunerar a soma dos custos variáveis e fixos. Dessa forma, os custos totais superaram as receitas obtidas no período. O componente do custo operacional efetivo com maior representatividade foi a alimentação. Por apresentar margem líquida positiva e resultado negativo, a propriedade tem condições de produzir de forma eficiente em médio prazo, porém, no longo prazo, o pecuarista tende a se descapitalizar.
\end{abstract}

Palavras-chave: Análise econômica; Bovinocultura leiteira; Ponto de equilíbrio.

\section{Production cost and profitability analysis in family dairy farming}

\begin{abstract}
Family farming has a significant economic and social contribution in Brazil, where it is present in most of the farms. In the State of Minas Gerais, there is a predominance of small dairy farmers, mainly in family farming. In this context, the objective was to identify the main components of the cost of production and to analyze the profitability of a family farm in that State. The data were collected during a period of 12 months, from January to December 2015, in a dairy farm located in the municipality of Conceição da Barra de Minas. Electronic data processing and profitability analysis considered gross and net margins and the result as indicators of economic efficiency. Revenues outpaced operating and variable costs, however, were not sufficient to pay the sum of variable and fixed costs. In this way, the total costs exceeded the revenues obtained in the period. The most representative effective operational cost component was the feed. Due to the positive net margin and the negative result, the farm is able to produce efficiently in the medium term, however, in the long term, the farmer tends to decapitalize.
\end{abstract}

Keywords: Breakeven point; Dairy farming; Economic analysis.

\footnotetext{
${ }^{1}$ Submetido em 07/06/2017 e aprovado em 18/06/2018

${ }^{2}$ Especialista em Extensão Ambiental para o Desenvolvimento Sustentável; Extensionista da EMATER-MG, Conceição da Barra de Minas Mina Gerais, CEP 36360-000; E-mail: jose.eustaquio@emater.mg.gov.br

${ }^{3}$ Doutor em Zootecnia; Professor Titular, Universidade Federal de Lavras (UFLA), Departamento de Medicina Veterinária, Lavras - Minas Gerais, CEP:37200-000; Bolsista do CNPq; E-mail: malopes@dmv.ufla.br

${ }^{4}$ Doutora em Administração; Professora Adjunta, Universidade Federal de Goiás (UFG), Centro de Gestão e Negócios, Catalão - Goiás, CEP 75704-020; E-mail: nadiacpereira@yahoo.com.br

${ }_{5}^{5}$ Doutor em Zootecnia; Professor Associado, Universidade Federal do Espírito Santo (UFES), Departamento de Zootecnia, Alegre - Espirito Santo, CEP 29500-000; E-mail: gercilio.almeida@ufes.br
}

Revista Agropecuária Técnica, Areia-PB, v. 39, n. 2, p. 191-201, 2018

DOI: https://doi.org/10.25066/agrotec.v39i2.34747 


\section{Introdução}

A agricultura familiar representa um meio de organização da produção agrícola, florestal, pesqueira, pastoral e aquícola. A sua gestão depende, predominantemente do trabalho familiar, de forma que a família e a fazenda estão interligadas, se desenvolvendo e combinando funções econômicas, ambientais, sociais e culturais (FAO, 2013).

Apesar de sua reconhecida importância para o sistema alimentar global, estudos no âmbito da agricultura familiar são escassos (Graeub et al., 2016). Dados divulgados no relatório The state of food and agriculture da Organização das Nações Unidas para Alimentação e Agricultura (FAO, 2014), para uma amostra de 30 países, mostraram que existem aproximadamente 500 milhões de agricultores familiares no mundo, responsáveis por $80 \%$ da produção mundial de alimentos. No Brasil, em 2006, foram identificadas 4.367.902 propriedades de agricultura familiar, o que representa $84,4 \%$ dos estabelecimentos brasileiros. Essas propriedades ocupavam uma área de 80,25 milhões de hectares, ou seja, 24,3\% da área ocupada pelos estabelecimentos agropecuários brasileiros (IBGE, 2006).

Na pecuária de leite no Brasil, a agricultura familiar também é predominante, pois foi responsável por $58 \%$ do total de leite produzido no país, de acordo com o último Censo Agropecuário, realizado em 2006 (IBGE, 2006).

Embora sendo o maior produtor de leite do país, levantamento publicado em 2007, revelou que aproximadamente $80 \%$ dos produtores do Estado de Minas Gerais produziam menos de 200 litros de leite/dia, o que demonstrou a predominância de pequenos produtores, principalmente em agricultura familiar, nessa atividade (Marcatti Neto et al., 2007).

Para a permanência dos produtores familiares na atividade é fundamental que as propriedades produtoras de leite apresentem viabilidade econômica, pois as novas gerações têm preferido buscar outras alternativas de trabalho nas cidades e têm abandonado a vida no campo (Ferrari et al, 2004).

Neste sentido, reconhecer os pontos falhos do sistema de produção a partir da análise dos custos de produção, é algo primordial, mas poucas pesquisas conduzidas no país apresentam análises de rentabilidade e mostram quais componentes exercem maiores representatividades no custo de produção do leite em propriedades em regime de agricultura familiar.

Considerando a importância deste segmento para o país e para o Estado de Minas Gerais e a necessidade de ter mais parâmetros auxiliares ao processo de tomada de decisões com vistas à obtenção de sucesso econômico na atividade, objetivou-se identificar os principais componentes do custo de produção e analisar a rentabilidade em uma propriedade produtora de leite em regime de agricultura familiar no Estado de Minas Gerais.

\section{Material e Métodos}

Os dados foram coletados durante um período de 12 meses, entre janeiro a dezembro de 2015, em um sistema de produção de leite localizado no município de Conceição da Barra de Minas, localizado na região dos Campos das Vertentes, Estado de Minas Gerais. O município possui 273 $\mathrm{km}^{2}$ e a população foi estimada em 3.954 habitantes, dos quais 1.161 residiam no meio rural. A atividade agropecuária destaca-se pela sua importância social, econômica e ambiental, contribuindo de forma expressiva para a criação de oportunidades de trabalho e renda (IBGE, 2016).

Na propriedade estudada, os animais eram, em sua maioria, mestiços (3/4 holandês-gir), sendo mantidos em regime de pastagem na época das águas (de novembro a abril), e silagem de milho na época da seca (maio a outubro), recebendo concentrado o ano todo no momento da ordenha. As vacas em lactação eram ordenhadas duas vezes ao dia, utilizando-se ordenhadeira do tipo balde ao pé.

Os valores referentes à produção, despesas realizadas e receitas apuradas foram registrados em cadernetas de campo. Os dados foram posteriormente cadastrados na planilha Custo de Produção para Bovino de Leite, utilizada para o processamento eletrônico dos dados, bem como para a análise de rentabilidade do sistema de produção. A planilha contemplou as duas estruturas de custo de produção: custo total, que envolve o custo fixo e variável, e custo

Revista Agropecuária Técnica, Areia-PB, v. 39, n. 2, p. 191-201, 2018

DOI: https://doi.org/10.25066/agrotec.v39i2.34747 
operacional, proposta por Matsunaga et al. (1976).

Para evitar duplicidade de lançamento de despesas, a análise não considerou a depreciação de matrizes, uma vez que o sistema avalia o custo de produção da atividade como um todo. Assim, além dos custos de cria e recria de fêmeas de reposição, também foram considerados os custos de manutenção de vacas secas (Lopes et al., 2004a).

Foi realizado o inventário completo dos bens do sistema de produção de leite, além de apurado o valor e vida útil de cada ativo, conforme preconizado por Lopes et al. (2004a). Posteriormente, essas informações foram alocadas em um dos seguintes grupos: benfeitorias, máquinas, veículos, equipamentos, implementos, ferramentas e rebanho.

Especificamente em relação às benfeitorias, cada uma foi medida, atribuído um estado de conservação e registrado um resumo do memorial descritivo, objetivando auxiliar na estimativa do valor no momento da coleta das informações. Em função da área, do estado de conservação e do padrão de acabamento, foi estimado um valor por $\mathrm{m}^{2}$ de construção. $\mathrm{O}$ valor considerado foi produto do valor do $\mathrm{m}^{2}$ pela área da benfeitoria (Lopes et al., 2004a).

Nas situações em que não se dispunha de informações referentes ao valor e à data de aquisição, para a estimativa dos valores atuais, bem como da vida útil restante, foi adotado o critério proposto por Lopes et al. (2004b), que consistia em analisar os bens, em função do estado de conservação. Assim, a partir dessa avaliação, eles foram enquadrados em um dos seguintes escores: ótimo, bom, regular e ruim, sendo seus valores atuais respectivamente estimados em 100, 75, 50 e $25 \%$, dos valores de mercados dos bens novos. Para a estimativa de vida útil restante, consideraram-se os percentuais de $100,75,50$ e $25 \%$, para os bens em ótimo, bom, regular e ruim estado de conservação.

Para calcular a remuneração do capital investido, aplicou-se a taxa de $6 \%$ ao ano e, para a remuneração da terra, optou-se pelo valor de arrendamento praticado na região, que foi de $2 \mathrm{~kg}$ de leite/ha/dia (Lopes et al., 2011). Os itens que compõem o custo operacional efetivo de produção do leite foram divididos em grupos: mão de obra, alimentação, sanidade, impostos, energia e despesas diversas (Lopes e Lopes, 1999).

Para o cálculo das lucratividades e rentabilidades foram adotadas as fórmulas: Lucratividade $1(\%)=$ Resultado/Receita total, Lucratividade $2(\%)=$ Margem líquida /Receita total, Rentabilidade $1(\%)=$ Resultado/(Total imobilizado + Custo operacional efetivo) e Rentabilidade $2(\%)=$ Margem líquida/(Total imobilizado + Custo operacional efetivo), de acordo com metodologias propostas por SEBRAE (1998) e Lopes et al. (2011a).

Os índices produtivos e econômicos foram comparados por meio de análises descritivas simples, utilizando planilhas Excel ${ }^{\circledR}$, e agrupados em tabelas, objetivando melhor comparação, discussão e apresentação dos resultados (Lopes et al., 2004a).

\section{Resultados e Discussão}

Na Tabela 1 são apresentados dados relativos à área e produção para a caracterização da propriedade avaliada. Observa-se que a propriedade apesar de não possuir grande extensão territorial produziu aproximadamente 293 litros de leite/dia durante o período avaliado, colocando-se em patamar de produção acima do relatado por Marcatti Neto et al. (2007) para cerca de $80 \%$ dos produtores do Estado de Minas Gerais.

Tabela 1 Caracterização da propriedade em agricultura familiar estudada, no município de Conceição da Barra de Minas-MG

\begin{tabular}{lc}
\hline \multicolumn{1}{c}{ Item } & Quantidade \\
\hline Área (ha) & 35 \\
Leite comercializado (kg/ano) & 102.534 \\
Leite consumido (kg/ano) & 4.570 \\
Total de leite produzido (kg/ano) & 107.104 \\
\hline
\end{tabular}

Na Tabela 2 estão discriminados os bens disponíveis na propriedade avaliada, bem como a representatividade de cada item no total de recursos disponíveis na mesma. O valor do patrimônio em terra representou 35,25\% do capital total imobilizado no sistema de produção. Lopes e Santos (2013) avaliando sistemas de produção de leite em semiconfinamento, similares ao sistema aqui avaliado, encontraram porcentagem do patrimônio em terra, de $31,10 \%$ do total do patrimônio. 
Tabela 2 Recursos disponíveis na propriedade em agricultura familiar estudada, no município de Conceição da Barra de Minas-MG, janeiro a dezembro de 2015

\begin{tabular}{lcc}
\hline \multirow{2}{*}{\multicolumn{1}{c}{ Recursos }} & \multicolumn{2}{c}{ Valor } \\
\cline { 2 - 3 } & $\mathbf{R} \mathbf{\$}$ & $\mathbf{\%}$ \\
\hline Valor do patrimônio em terra & $122.500,00$ & 35,25 \\
Valor do patrimônio sem terra & $225.000,00$ & 64,75 \\
Valor em benfeitorias & $58.000,00$ & 16,70 \\
Valor em equipamentos & 700,00 & 0,20 \\
Valor em ferramentas & $2.000,00$ & 0,57 \\
Valor em máquinas & $18.300,00$ & 5,27 \\
Valor em veículos & $2.000,00$ & 0,57 \\
Valor do rebanho & $144.000,00$ & 41,44 \\
Valor total imobilizado & $347.500,00$ & \\
Total imobilizado/ha & $9.928,00$ & \\
\hline
\end{tabular}

O valor investido em animais $(41,11 \%)$ foi o item com maior representatividade do patrimônio sem considerar a terra, seguido pelas benfeitorias $(16,7 \%)$, máquinas $(5,27 \%)$, ferramentas $(0,57 \%)$, veículos $(0,57 \%)$ e equipamentos $(0,20 \%)$. O valor investido em animais evidencia a importância do cuidado que se deve ter com os mesmos, como, por exemplo, no momento da aquisição, no manejo sanitário e zootécnico, dentre outros, proporcionando condições para que se possa ter a máxima produtividade por área e, consequentemente, maior e mais rápido retorno do capital. Os valores investidos em animais são considerados como sendo custos fixos; portanto, deve-se atingir altas produções individuais para que possam ser diluídos, refletindo em baixos percentuais no custo total (Lopes et al., 2011).

O valor de capital imobilizado por hectare pode ser utilizado como indicador de intensificação dos sistemas de produção. Esse indicador pode variar em consequência de alguns fatores, tais como: o valor da terra entre as diferentes regiões; taxa de lotação; valor dos animais; maior uso de tecnologias; e a existência de recursos obsoletos (Lopes et al., 2011).

Na Tabela 3 encontra-se o resumo da análise de rentabilidade realizada na propriedade estudada. A receita total, durante o período de estudo, foi de R $\$ 107.920,00$, o que correspondeu à soma dos valores apurados com a venda de leite $(94,81 \%)$ e animais $(5,19 \%)$.

A participação da receita do leite foi maior do que a obtida por Ferrazza et al. (2015), que encontraram a receita média de $85,5 \%$ com a venda do leite em sistemas familiares avaliados nos Estados de Minas Gerais e Rio de Janeiro, e também superior à encontrada por Lopes et al. (2004a) em avaliação de propriedades na região de Lavras - MG, que encontraram $86,94 \%$ para a participação do leite na receita total da propriedade.

Lopes et al. (2016), ao analisarem o percentual da receita obtida com a venda do leite em propriedades no Estado do Rio de Janeiro, encontraram os valores, também inferiores aos deste estudo, de 86,92, 85,72 e 79,59\% para propriedades de baixo, médio e alto nível tecnológico, respectivamente.

A maior participação da receita com leite no presente estudo se justifica pela pequena venda de animais realizada pela propriedade no exercício avaliado, o que gerou participação deste item na receita, inferior aos $14,5 \%$ obtidos por Ferrazza et al. (2015), 12,45\% obtidos por Lopes et al. (2004a) e 12,91, 13,97 e 18,82\%, obtidos por Lopes et al. (2016).

Não se considerou na análise de rentabilidade a receita obtida com a venda do subproduto esterco que foi de $0,61 \%$ do valor da receita obtida com a venda de leite e animais. Valores semelhantes, variando de 0,35 a $0,84 \%$, foram relatados por Reis et al. (2001), Lopes et al. (2004a) e Lopes et al. (2006).

A venda de subprodutos como o esterco bovino, pode ser uma fonte adicional de receita na pecuária de leite, mas a utilização do mesmo na propriedade também pode contribuir para a diminuição dos custos com adubação química de forrageiras (Lopes et al., 2011). Nas visitas à propriedade, foi observado que houve desperdício desse subproduto, em consequência de condições inadequadas para seu armazenamento.

O Custo Operacional Total (COT) foi de R \$ 83.812,51, obtido pela soma do custo operacional efetivo ( $\mathrm{R} \$ 58.086,41$ ), que foi o desembolso, com o custo de depreciação dos bens patrimoniais $(\mathrm{R} \$ 5.238,10)$ e com a remuneração da mão de obra familiar (R\$20.488,00) (Tabela 3). Embora a depreciação não seja um desembolso, o seu valor representa uma reserva de caixa que deveria ser feita para se repor os bens patrimoniais ao final de sua vida útil (Lopes et al., 2004a). A receita do período permitiu que essa reserva fosse feita, bem como que a mão de obra familiar fosse remunerada. Isso significa que, ao final da vida

Revista Agropecuária Técnica, Areia-PB, v. 39, n. 2, p. 191-201, 2018

DOI: https://doi.org/10.25066/agrotec.v39i2.34747 
útil do bem, em permanecendo constantes as condições atuais, o pecuarista teria recursos monetários para a aquisição de um novo bem substituto, não havendo descapitalização em médio prazo (Lopes et al., 2004a).

O custo total (CT), que representa a soma dos custos fixos e dos custos variáveis, foi de $\mathrm{R} \$$ 121.678,00 (Tabela 3). A diferença entre o custo total e a receita, que foi de $\mathrm{R} \$ 13.757,63(\mathrm{R} \$$ 121.678,00 - R \$107.920,37), mostra que todos os custos variáveis $(\mathrm{CV})$ puderam ser pagos e que a reserva referente à depreciação pôde ser realizada, mas o capital investido em bens e terra não foi completamente remunerado. Com esse fato, evidencia-se que o sistema de produção estudado está se descapitalizando ao longo do tempo.

Tabela 3 Resumo da análise de rentabilidade em propriedade em agricultura familiar localizada no município de Conceição da Barra de Minas-MG, janeiro a dezembro de 2015

\begin{tabular}{|c|c|c|}
\hline \multirow{2}{*}{ Especificação } & \multicolumn{2}{|c|}{ Valor } \\
\hline & $(\mathbf{R} \$)$ & $\%$ \\
\hline Receitas & $107.920,00$ & 100,0 \\
\hline Leite & $102.320,00$ & 94,81 \\
\hline Animais & $5.600,00$ & 5,19 \\
\hline Custo operacional total (COT) & $83.812,51$ & 100,0 \\
\hline Custo operacional efetivo (COE) & $58.086,41$ & 69,31 \\
\hline Custo com depreciação & $5.238,10$ & 6,25 \\
\hline Mão de obra familiar & $20.488,00$ & 24,44 \\
\hline Custo total (CT) & $121.678,00$ & 100,0 \\
\hline Custos fixos (CF) & $31.865,48$ & 26,19 \\
\hline Remuneração da terra & $12.748,38$ & 40,00 \\
\hline Remuneração do capital investido & $13.500,00$ & 42,37 \\
\hline Impostos fixos & 379,00 & 1,19 \\
\hline Depreciação & $5.238,10$ & 16,44 \\
\hline Custos variáveis $(\mathrm{CV})$ & $89.812,69$ & 73,81 \\
\hline Custo operacional efetivo (sem impostos) & $57.707,41$ & 64,25 \\
\hline Mão-de-obra familiar & $20.488,00$ & 22,81 \\
\hline Remuneração do capital de giro & $11.617,28$ & 12,94 \\
\hline Margem bruta & $49.833,96$ & \\
\hline Margem líquida & $24.107,86$ & \\
\hline Resultado (lucro ou prejuízo) & $-13.757,81$ & \\
\hline Margem bruta/kg de leite & 0,49 & \\
\hline Margem líquida/kg de leite & 0,23 & \\
\hline Resultado (lucro ou prejuízo)/kg de leite & $-0,13$ & \\
\hline Lucratividade $1^{1}$ & & $-12,75$ \\
\hline Rentabilidade $1^{2}$ & & $-3,39$ \\
\hline Lucratividade $2^{3}$ & & 22,34 \\
\hline Rentabilidade $2^{4}$ & & 5,94 \\
\hline Variação patrimonial do rebanho & $10.000,00$ & \\
\hline Custo operacional total $/ \mathrm{kg}$ de leite & 0,82 & \\
\hline Custo operacional efetivo/kg de leite & 0,57 & \\
\hline Custo total $/ \mathrm{kg}$ de leite & 1,19 & \\
\hline Custo fixo/kg de leite & 0,31 & \\
\hline Custo variável $/ \mathrm{kg}$ de leite & 0,88 & \\
\hline Preço médio do kg leite & 1,00 & \\
\hline
\end{tabular}

${ }^{1}$ Lucratividade 1: (resultado/receita total) x 100;

${ }^{2}$ Rentabilidade 1: (resultado/(custo operacional efetivo + imobilizado total)) x 100;

${ }^{3}$ Lucratividade 2: (margem líquida/receita total) x 100;

${ }^{4}$ Rentabilidade 2: (margem líquida/(total imobilizado + custo operacional efetivo)) x 100 .

Os custos fixos (CF), que são compostos pela remuneração da terra, remuneração do capital investido, remuneração do empresário, impostos considerados fixos (ITR, IPVA, licenciamento e seguro obrigatório de veículos) e depreciação do patrimônio, totalizaram $\mathrm{R} \$ 31.865,48$ (Tabela 3). 
Esses custos não representaram desembolso (com exceção dos impostos), mas representaram o que a atividade deveria remunerar para ser competitiva com outras atividades econômicas e não descapitalizar o pecuarista ao longo dos anos. Se esses custos não forem contemplados, o pecuarista poderá, em longo prazo, perder o patrimônio e se endividar (Lopes et al., 2004a). Tais custos fixos, que representaram $26,19 \%$ do custo total, foram similares aos $24,10 \%$ encontrados por Lopes et al. (2011b) e os 27,20\% encontrados por Lopes et al. (2008a) e também por Ferrazza et al. (2015). De fato, a representatividade dos custos fixos no custo total se torna mais diluída quanto maior for o volume de leite produzido.

É importante ressaltar que, independentemente da quantidade produzida, não havendo aquisição nem venda de bens e nem aumento de impostos, os custos fixos permanecerão constantes. Para que esses custos sejam menos representativos no custo total, tanto a produção como a produtividade devem ser aumentadas, atingindo uma economia de escala. $\mathrm{O}$ aumento da eficiência produtiva, otimizando o uso dos bens para produção, e a produção em escala é uma alternativa. De acordo com Lopes et al. (2006), essas práticas podem diminuir o custo operacional total (COT) por quilograma de leite.

Os custos variáveis que são compostos pelo custo operacional efetivo, excetuando impostos considerados fixos (ITR e IPVA), pela remuneração do capital de giro e pela mão de obra familiar, neste estudo, totalizaram $\mathrm{R} \$ \mathbf{8 9 . 8 1 2 , 6 9}$ (Tabela 3) e equivaleram a $73,81 \%$ do custo total. Em análise de rentabilidade durante um período de cinco anos, em propriedade com baixos índices de eficiência no Estado de Minas Gerais, Prado et al. (2007) encontraram custos variáveis médios de $50,70 \%$ do custo total da produção de leite. Arêdes et al. (2006), em análise de dois anos na região de Viçosa - MG, encontraram a média de $69,67 \%$ para os custos variáveis médios nas propriedades avaliadas. Contudo, conforme observado por Silva et al. (2008), os custos variáveis tendem a apresentar maiores valores proporcionais por litro produzido, em propriedades que adotam maiores níveis de suplementação e intensificação da produção.

Observa-se pelos indicadores de eficiência econômica margem bruta (receita bruta menos custo operacional efetivo) e líquida (receita bruta menos o custo operacional total) que tais resultados foram satisfatórios (positivos), evidenciando que a atividade leiteira, neste sistema, tem condições de sobreviver em curto e médio prazo, respectivamente (Tabela 3). Altafin et al. (2011), em um trabalho realizado em assentamentos de reforma agrária no município de Unaí - MG, com 16 produtores de leite, avaliaram a eficiência produtiva utilizando a análise envoltória de dados. Como principais achados, foram identificados quatro produtores com máxima eficiência, sendo a eficiência média dos produtores ineficientes de $77 \%$. Nesse caso estudado, a receita foi suficiente para cobrir as despesas operacionais, mas não para fazer as reservas necessárias para substituição dos bens ao término de suas vidas úteis (depreciação), estando, portanto, o produtor se descapitalizando a cada ciclo produtivo.

Quando se analisa pelo indicador de eficiência econômica, resultado (receita bruta menos custo total), verifica-se que esse foi insatisfatório (Tabela 3), evidenciando que a atividade leiteira não conseguiu remunerar $\mathrm{o}$ capital. A lucratividade 1 foi de $-12,75 \%$, o que significa que, para cada $R \$ 100,00$ investidos, houve uma perda de $\mathrm{R} \$ 12,75$. A rentabilidade 1 foi de $3,39 \%$. A lucratividade 2 foi de $22,34 \%$, por considerar a margem líquida sobre a receita total, enquanto que a rentabilidade 2 foi de $5,94 \%$ por considerar a margem líquida sobre o total imobilizado mais custo operacional efetivo (Lopes et al., 2011), podendo-se comparar com atividades diferentes, mostrando a melhor opção de investimento, como, por exemplo, a caderneta de poupança, que, no período de 12 meses, obteve uma taxa real de juros de $6 \%$. Nesse caso, a aplicação em caderneta de poupança teria sido melhor negócio para o pecuarista.

Na Tabela 3 são apresentados ainda, os custos médios de produção por quilograma de leite do produtor, em um período de 12 meses. Verificase que o valor médio de venda de $\mathrm{R} \$ 1,00$ foi suficiente para cobrir as despesas operacionais efetivas $(\mathrm{R} \$ 0,57)$ e o custo variável $(\mathrm{R} \$ 0,88)$. Quando tomado como referência o custo total (soma do custo fixo e variável) de $\mathrm{R} \$ 1,19$, a diferença de $\mathrm{R} \$ 0,12$ ( $\mathrm{R} \$ 1,00$ - $\mathrm{R} \$ 0,88)$ é suficiente para cobrir apenas $38,7 \%$ das despesas fixas, nas quais está incluída a remuneração do

Revista Agropecuária Técnica, Areia-PB, v. 39, n. 2, p. 191-201, 2018

DOI: https://doi.org/10.25066/agrotec.v39i2.34747 
capital investido. Destaca-se, ainda, que embora o preço médio recebido por $\mathrm{kg}$ leite no presente estudo tenha sido de $\mathrm{R} \$ 1,00$, a média praticada no Estado de Minas Gerais, em 2015, foi de R\$ 0,97 (CEPEA, 2016).

O custo operacional efetivo da propriedade representou o desembolso médio no período de 12 meses, feito pelo produtor, para custear a atividade. Os itens que compõem o custo operacional efetivo de produção do leite foram divididos em grupos, cada qual responsável pelos percentuais encontrados na Tabela 4. A divisão das despesas em grupos, de acordo com Lopes e Lopes (1999), permite o monitoramento das despesas do sistema de produção de leite, auxiliando o técnico e o produtor em uma análise mais detalhada.

A alimentação apresentou grande representatividade e foi responsável por 79,96\% das despesas operacionais efetivas (Tabela 4). Ferrazza et al. (2015) obtiveram a média de $67,90 \%$ para a participação da alimentação no custo operacional efetivo de propriedades familiares. O percentual aqui encontrado também está acima do percentual médio encontrado por Lopes et al. (2004a), de 59,95\%, e por Lopes et al. (2016), que encontraram $63,32 \%$ e $62,69 \%$ para sistemas de produção com baixo e médio nível tecnológico, respectivamente e também acima da média de $57,33 \%$, obtida por Lopes et al. (2008b).Vale salientar que o sistema de produção utilizou suplementação concentrada durante todo o ano e, na época da seca, suplementação volumosa e concentrada, além de ter gasto com recuperação de pastagens.

Tabela 4 Representatividade de cada grupo de despesas no custo operacional efetivo (COE) da propriedade em agricultura familiar estudada, no município de Conceição da Barra de Minas - MG, janeiro a dezembro de 2015

\begin{tabular}{lc}
\hline \multicolumn{1}{c}{ Especificação } & Valor (\%) \\
\hline Alimentação & 79,96 \\
Energia & 3,33 \\
Mão de obra & 0,52 \\
Ordenha & 1,04 \\
Sanidade & 4,16 \\
Inseminação artificial & 1,48 \\
Impostos fixos (ITR, IPVA, licenciamento e & 0,65 \\
seguro do veículo) & 4,22 \\
Aluguel de pastos & 4,64 \\
Despesas diversas & $\mathbf{1 0 0 , 0 0}$ \\
\hline Total
\end{tabular}

No grupo energia (combustível e energia elétrica), o valor de $3,33 \%$ de participação no custo operacional efetivo (Tabela 4) foi próximo aos valores encontrados por Lopes et al. (2016), que verificaram variação de 2,70 a $4,25 \%$ em propriedades com diferentes níveis tecnológicos. $\mathrm{O}$ valor mínimo foi da unidade familiar que não possuía ordenhadeira e as estruturas das instalações eram mínimas. O valor máximo foi observado em uma propriedade com sistema de produção bem rudimentar, em que o rebanho não possui especialização para a produção de leite e o produtor não reside na propriedade com a sua família. Moura et al. (2010) encontraram a participação média de $4,56 \%$ do grupo energia no custo operacional efetivo de seis propriedades analisadas no Estado da Paraíba, valor também próximo ao do presente estudo.

O fato de estar distante em torno de 60 quilômetros da sede do município, onera o grupo energia pelos gastos com combustível para deslocamento. Fatos como este podem inviabilizar o sistema de produção de leite, pois os proprietários precisam ter consciência que todos os gastos incluídos no custo de produção devem ser aqueles relacionados especificamente para a atividade leiteira. Gastos pessoais ou com outras atividades produtivas, devem ser considerados de forma específica para cada demanda. Uma alternativa aconselhada nessas situações é a implantação de centros de custos. Os centros de custos permitem a identificação com clareza de quais atividades podem apresentar maior rentabilidade, assim como permite criar critérios justos para rateios de despesas.

Quanto à mão de obra contratada, o percentual de $0,52 \%$ do custo operacional efetivo (Tabela 4 ) está abaixo da média encontrada por outros pesquisadores. Tal valor pode ser explicado pelo fato do sistema de produção ter utilizado mão de obra familiar, diminuindo, então, o desembolso e reduzindo a contratação de pessoal. Essa evidência é corroborada pela baixa relação vaca/homem $(12,67: 1)$ encontrada neste estudo (Tabela 5). Contudo, Ferrazza et al. (2015) encontraram o valor médio ainda inferior de 6,3 vacas por homem em sistemas familiares de produção. A produção diária de leite por mão de obra permanente de 195,62 kg está aquém das obtidas por Schiffler et al. (1999), que relataram $246,12 \mathrm{~kg}$. 
Quanto à representatividade do grupo ordenha (aquisição de soluções pré e pós dipping, detergentes ácidos e alcalinos, papel toalha, desinfetantes e demais produtos utilizados na ordenha), o valor obtido $(1,04 \%)$ foi próximo ao $1,03 \%$ encontrado por Lopes et al. (2006) para rebanhos com alto nível tecnológico (Tabela 4). Moura et al. (2010) relataram média de $0,76 \%$ do custo operacional efetivo para despesas com ordenha; abaixo do valor obtido neste estudo. Lopes et al. (2004b) verificaram que cuidados com a obtenção higiênica do leite não têm recebido a devida atenção por parcela significativa de produtores de leite, pois, ao fazerem o levantamento de todas as despesas operacionais efetivas em 16 propriedades leiteiras do sul de Minas Gerais, constataram que em 50\% delas não houve nenhuma despesa com aquisição de soluções pré e pós-dipping, detergentes ácidos e alcalinos, papel toalha, desinfetantes e demais produtos utilizados na ordenha.

As despesas com sanidade (Tabela 4) são aquelas relacionadas ao uso de medicamentos curativos (antibióticos, antitóxicos, estimulantes etc.), medicamentos preventivos (vacinas, antibióticos usados na terapia de vacas secas, hormônios, antiparasitários e outros) e exames sanitários. $\mathrm{O}$ valor da representatividade verificado no presente estudo $(4,16 \%)$ foi inferior aos de Ferrazza et al. (2015), que relataram a média de 5,80\%, e aos de Lopes et al. (2016), os quais variaram de 4,77 a $5,37 \%$ do custo operacional efetivo. Não há na literatura um valor considerado ideal para sanidade e preconizar valor zero para este item seria uma incoerência, pois, um percentual deve ser investido em prevenção, uma vez que, segundo Demeu et al. (2015), a prevenção se torna mais econômica do que o uso de medicamentos curativos.

Quanto aos impostos considerados fixos, como o ITR e IPVA, representaram apenas $0,65 \%$ do custo operacional efetivo (Tabela 3), próximo dos 0,83\% encontrados por (Lopes et al., 2004a), em propriedades avaliadas no município de Lavras - MG, e também do valor de $0,75 \%$ encontrado por Almeida Jr. et al. (2002), em um sistema intensivo de produção de leite no Estado de São Paulo. Ferrazza et al. (2015) encontraram a representatividade de $0,30 \%$ desses impostos em sistemas familiares.
Foram consideradas despesas diversas aquelas que não se enquadram nos grupos mencionados anteriormente, tais como, taxas e impostos variáveis em função da produção, despesas com manutenção de benfeitorias, máquinas $\mathrm{e}$ equipamentos.

$\mathrm{Na}$ Tabela 5, podem ser observados outros índices técnicos e gerenciais. Ferrazza et al. (2015), destacaram que, considerando-se a grande heterogeneidade da cadeia produtiva do leite no Brasil e o caráter dinâmico inerente ao ambiente de produção, a identificação, a quantificação e o estabelecimento de índices técnico-gerenciais e econômicos de referência são de interesse prático para o meio profissional.

Tabela 5 Índices técnicos e gerenciais da propriedade em agricultura familiar estudada, no município de Conceição da Barra de Minas - MG, janeiro a dezembro de 2015

\begin{tabular}{lc}
\hline \multicolumn{1}{c}{ Especificação } & Valor \\
\hline Depreciação/COT ${ }^{1}(\%)$ & 6,25 \\
COE $/$ COT (\%) & 69,31 \\
Mão de obra familiar/COT (\%) & 24,45 \\
Custo Fixo/Custo Total (\%) & 26,19 \\
Custo Variável/Custo Total (\%) & 73,81 \\
Depreciação/Custo Total (\%) & 4,30 \\
Quantidade de vacas em lactação/ha & 0,54 \\
Quantidade de mão de obra & 1,50 \\
Relação vacas/mão de obra & 12,67 \\
Produção de leite diária (kg de leite) & 293,94 \\
Produtividade vaca/dia (kg de leite) & 15,44 \\
Produção de leite/ha/ano (kg de leite) & $2.929,54$ \\
Ponto de equilíbrio (kg de leite) & $261.223,18$ \\
\hline TCOT: custo operacional total ${ }^{2}$ COE: custo operacional efetivo.
\end{tabular}

${ }^{1}$ COT: custo operacional total; ${ }^{2} \mathrm{COE}$ : custo operacional efetivo.

No presente estudo, a depreciação foi responsável por $6,25 \%$ do COT, inferior aos $14,37 \%$ obtidos por Lopes et al. (2004a) e 11,90\% encontrados por Ferrazza et al. (2015). Embora na literatura não exista informação sobre qual seria um bom valor para esse indicador técnico, podese dizer que a eficiência de utilização dos bens do patrimônio do sistema de produção estudado nesta pesquisa foi superior ao sistema estudado por Lopes et al. (2004a). Segundo Lopes et al. (2008b), embora não seja um desembolso, o valor referente à depreciação representa uma reserva de caixa que deveria ser feita para repor os bens patrimoniais (instalações, equipamentos etc.) ao final de sua vida útil. Isso significa que, ao final da vida útil do bem, em permanecendo constante as condições atuais, o pecuarista teria recursos

Revista Agropecuária Técnica, Areia-PB, v. 39, n. 2, p. 191-201, 2018

DOI: https://doi.org/10.25066/agrotec.v39i2.34747 
monetários para a aquisição de um novo bem substituto, não havendo descapitalização em médio prazo.

A quantidade média de vacas em lactação durante esse período foi de 19, em uma área de 35 hectares destinados à produção de leite, correspondendo a uma taxa de lotação de 0,54 vacas/ha. Esse valor evidencia que as áreas estão com suas capacidades de utilização ociosas; o ideal seria acima de $2 \mathrm{UA} / \mathrm{ha}$, segundo Costa (2007). A produtividade de leite por ha/ano, de $2.929,54 \mathrm{~kg}$, foi baixa, quando comparada às recomendadas por Costa (2007), que seriam acima de $7.000 \mathrm{~kg}$ leite/ha/ano. Com esses índices, evidencia-se que muitos esforços gerenciais e até mesmo tecnológicos devem ser adotados, objetivando aumentar a produção diária sem elevar o custo variável médio, que, uma vez majorado, aumentará ainda mais o ponto de equilíbrio. Uma alternativa é aumentar o número de matrizes, otimizando assim as despesas com mão de obra, inseminação artificial, impostos considerados fixos, energia e diversas. Tais despesas, aumentando-se a produção, não serão majoradas (Lopes et al., 2004b).

A mão de obra, com produtividade de 195,62 litros de leite dia/homem, também está ociosa, pois, segundo Costa (2007), o desempenho de produção de um homem, pode chegar a 400 litros de leite/dia. A produção média diária de leite foi de $293,94 \mathrm{~kg}$, com produtividade de $15,44 \mathrm{~kg}$ por matriz em lactação.

\section{Conclusão}

As receitas obtidas pela propriedade em agricultura familiar foram superiores aos custos operacionais e aos custos variáveis do sistema de produção, no entanto, não foram suficientes para contemplarem a remuneração da soma dos custos variáveis e custos fixos envolvidos. Dessa forma, os custos totais superaram as receitas obtidas no período;

Os itens componentes do custo operacional efetivo que exerceram maiores representatividades sobre os custos da atividade leiteira foram, em ordem decrescente, a alimentação, despesas diversas, aluguel de pasto, sanidade, energia, inseminação artificial, ordenha, impostos considerados fixos e mão de obra contratada;
Os custos com alimentação, baixa produtividade da mão de obra familiar causada pela baixa quantidade de animais ordenhados e baixa unidade animal por hectare são pontos de estrangulamento observados que contribuem para o aumento do custo de produção da propriedade leiteira analisada;

A análise de rentabilidade mostrou que, por apresentar margem líquida positiva e resultado negativo, a propriedade tem condições de continuar a produzir em médio prazo; porém, em longo prazo, o pecuarista tende a se descapitalizar, inviabilizando a continuidade do sistema de produção.

\section{Agradecimentos}

Os autores agradecem à EMATER - MG, por ter possibilitado a realização desta pesquisa, e ao CNPq pela concessão de bolsa de produtividade ao segundo autor.

\section{Referências}

Almeida Júnior, G. A.; Lopes, M. A.; Pinatto, F. Efeito da venda de animais na rentabilidade de um sistema intensivo de produção de leite tipo B no estado de São Paulo. In: REUNIÃO ANUAL DA SOCIEDADE BRASILEIRA DE ZOOTECNIA, 39., 2002, Recife. Anais... Recife: [s.n.], 2002. CD-ROM.

Altafin, I.; Pinheiro, M. E. F.; Valone, G. V.; Gregolin, A. C. Produção familiar de leite no Brasil: um estudo sobre os assentamentos de reforma agrária no município de Unaí (MG). Revista UNI, Imperatriz, v.1, n.1, p.31-49, 2011. Disponível em: < http://www.unisulma.edu.br/Revista_UNI_artigo2_p31_4 9.pdf >. Acesso em 10 de março de 2016.

Arêdes, A.; Silveira, S. F. R.; Lima, A. A. T. F. C.; Arêdes, A. F.; Pires, S. V. Análise de custos na pecuária leiteira: um estudo de caso das propriedades assistidas pelo Programa de Desenvolvimento da Pecuária Leiteira da região de Viçosa. Custos e Agronegócio Online, v.2, n.1, p.45-68, 2006. http://www.custoseagronegocioonline.com.br/numero1v2 Analise\%20de\%20custos.pdf

Centro de Estudos Avançados em Economia Aplicada - CEPEA. Valores nominais do leite - R\$/Litro em 2015. Piracicaba: USP/ESALQ, 2016. Disponível em: < 
http://cepea.esalq.usp.br/leite/?page=155 >. Acesso em: 10 de março de 2016.

Costa, J. L. Avaliação de indicadores técnicos de eficiência e renda da propriedade leiteira. In: Torres, R. A. (Editores). Tecnologias para o desenvolvimento da pecuária de leite familiar do Norte de Minas e Vale do Jequitinhonha. Juiz de Fora: Embrapa Gado de Leite, 2007. Cap.3, p.39-51.

Demeu, F. A.; Lopes, M.A.; Rocha, M. C. M. B.; Costa, G. M.; Santos, G.; Franco Neto, A. Influência da escala de produção no impacto econômico da mastite em rebanhos bovinos leiteiros. Revista Ceres, v.62, n.2. p.167-174, 2015. http://dx.doi.org/10.1590/0034$\underline{737 X 201562020006}$

Ferrari, D. L.; Abramovay, R.; Silvestro, M. L.; Mello, M. A.; Testa, V. M. Dilemas e estratégias dos jovens rurais: ficar ou partir? Estudos Sociedade e Agricultura, v.12, n.2, p.237-271, 2004.

https://revistaesa.com/ojs/index.php/esa/article/view/251/ $\underline{247}$

Ferrazza, R. A.; Lopes, M. A.; Bruhn, F. R. P.; Moraes, F. Índices de desempenho zootécnico e econômico de sistemas de produção de leite com diferentes tipos de mão de obra. Ciência Animal Brasileira, v.16, n.2, p.193-204, 2015. http://dx.doi.org/10.1590/1089-6891v16i225878

Food and Agriculture Organization - FAO. Master Plan. Rome: FAO, 2013. Disponível em:

http://www.fao.org/fileadmin/user_upload/iyff/docs/Final _Master_Plan_IYFF_2014_30-05.pdf >. Acesso em: 17 de março de 2017.

Food and Agriculture Organization - FAO. The state of food and agriculture 2014: Innovation in family farming. Rome: FAO, 2014. Disponível em: < http://www.fao.org/3/ai4040e.pdf $>$. Acesso em: 17 de março de 2017.

Graeub, B. E.; Chappell, M. J.; Wittman, H.; Ledermann, S.; Kerr, R. B.; Gemmill-Herren, B. The State of Family Farms in the World. World Development, v.87, n.1, p.1-15, 2016. https://doi.org/10.1016/j.worlddev.2015.05.012

IBGE - Instituto Brasileiro de Geografia e Estatística. Censo Agropecuário 2006. Rio de Janeiro: IBGE, 2006. Disponível em: < http://www.ibge.gov.br/home/estatistica/economia/agrope cuaria/censoagro/ $>$. Acesso em: 15 de janeiro de 2017.

IBGE - Instituto Brasileiro de Geografia e Estatística. Cidades. Rio de Janeiro: IBGE, 2016. Disponível em: < https://cidades.ibge.gov.br/brasil/mg/conceicao-da-barrade-minas/panorama >. Acesso em: 10 de março de 2016.

Lopes, M. A.; Cardoso, M. G.; Carvalho, F. M.; Lima, A. L. R.; Dias, A. S.; Carmo, E. A. Resultados econômicos da atividade leiteira na região de Lavras (MG) nos anos 2004 e 2005: um estudo multicasos. Arquivo Brasileiro de Medicina Veterinária e Zootecnia, v.60, n.2, p.428-435, 2008b. http://dx.doi.org/10.1590/S0102$\underline{09352008000200023}$

Lopes, M. A.; Carmo, E. A.; Carvalho, F. M. Análise de rentabilidade de uma empresa com opção de comercialização de queijo ou leite. Arquivo Brasileiro de Medicina Veterinária e Zootecnia, v.58, n.4, p.642-647, 2006. http://dx.doi.org/10.1590/S0102-09352006000400028

Lopes, M. A.; Dias, A. S.; Carvalho, F. M.; Lima, A. L. R.; Cardoso, M. G.; Carmo, E. A. Efeito da escala de produção nos resultados econômicos de sistema de produção de leite na região de Lavras (MG) em 2004 e 2005. Archivos Latinoamericanos de Producción Animal, v.16, n.3, p.121-129, $2008 \mathrm{a}$. http://dx.doi.org/10.1590/S0102-09352008000200023

Lopes, M. A.; Gomide, D. R.; Neto, A. F.; Santos, G. Resultados econômicos de um sistema de produção de leite na região de Varginha - Sul de Minas Gerais. Boletim de Indústria Animal, v.68, n.1, p.07-15, 2011b. https://www.bvsvet.org.br/vetindex/periodicos/boletim-de-industriaanimal/68-(2011)-1/resultados-economicos-de-umsistema-de-producao-de-leite-na-regiao-de-/

Lopes, M. A.; Lima, A. L. R.; Carvalho, F. M.; Reis, R. P.; Santos, I. C.; Saraiva, F. H. Controle gerencial e estudo da rentabilidade de sistemas de produção de leite na região de Lavras (MG). Ciência e Agrotecnologia, v.28, n.4, p.883892, 2004a. http://dx.doi.org/10.1590/S141370542004000400022

Lopes, M. A.; Lima, A. L. R.; Carvalho, F. M.; Reis, R. P.; Santos, I. C.; Saraiva, F. H. Efeito do tipo de sistema de criação nos resultados econômicos de sistemas de produção de leite na região de Lavras (MG). Ciência e

Revista Agropecuária Técnica, Areia-PB, v. 39, n. 2, p. 191-201, 2018

DOI: https://doi.org/10.25066/agrotec.v39i2.34747 
Agrotecnologia, v.28, n.5, p.1177-1189, 2004b. $\underline{70542004000500028}$

Lopes, M. A.; Lopes, D. C. F. Desenvolvimento de um sistema computacional para cálculo do custo de produção do leite. Revista Brasileira de Agroinformática, v.2, n.1, p.1-12, 1999.

Lopes, M. A.; Moraes, F.; Carvalho, F. M.; Peres, A. A. C.; Bruhn, R. P.; Reis, E. M. B. Effect of technical indexes on cost-effectiveness in dairy farms participating in the "Balde Cheio" program at different stages of production. Semina: Ciências Agrárias, v.37, n.6, p.42354242, 2016. http://dx.doi.org/10.5433/16790359.2016v37n6p4235

Lopes, M. A.; Santos, G. Análise de rentabilidade de fazendas leiteiras em regime de semiconfinamento com alta produção diária. Informações Econômicas, v.43, n.3, p.65-74, 2013.

http://www.iea.sp.gov.br/ftpiea/publicacoes/ie/2013/tec70613.pdf

Lopes, M. A; Santos, G.; Resende, M. C; Carvalho, F. M.; Cardoso, M. G. Estudo da rentabilidade de sistemas de produção de leite na região de Nazareno (MG). Ciência Animal Brasileira, v.12, n.1, p.58-69, 2011a. http://dx.doi.org/10.5216/cab.v12i1.7725

Marcatti Neto, A.; Gonçalves Filho, A. F.; Godoy, M.; Amaral, R.; Azevedo, N. A.; Silva, J. B. Diagnóstico da pecuária leiteira do município de Barroso. Belo Horizonte: EPAMIG, 2007. 24p.

Matsunaga, M.; Bemelmans, P. F.; Toledo, P. E. N; Dulley, R. D.; Okawa, H.; Pedroso, I. A. Metodologia de custo de produção utilizado pelo IEA. Agricultura em São Paulo, v.23, n.1, p.123-139,

1976. http://www.iea.sp.gov.br/ftpiea/rea/tomo1_76/artigo3.pdf

Moura, J. F. P.; Pimenta Filho, E. C.; Gonzaga Neto, S.; Leite, S. V. F.; Guilhermino, M. M.; Menezes, M. P. C. Análise econômica da exploração de leite no cariri paraibano. Acta Scientiarum. Animal Sciences, v.32, n.2, p.225-231, 2010. http://dx.doi.org/10.4025/actascianimsci.v32i2.7115

Prado E.; Geraldo, L. G.; Cardoso, B. M. Rentabilidade da exploração leiteira em uma propriedade durante cinco anos. Arquivo Brasileiro de Medicina Veterinária e Zootecnia, v.59, n.2, p.501-507, 2007. http://dx.doi.org/10.1590/S0102-09352007000200034

Reis, R. P.; Medeiros, A. L.; Monteiro, L. A. Custo de produção da atividade leiteira na região sul de Minas Gerais. Organizações Rurais e Agroindustriais, v.3, n.2, p.45-54, 2001.

Schiffler, E. A.; Mâncio, A. B.; Gomes, S. T. Efeito da escala de produção nos resultados de produção de leite B no estado de São Paulo. Revista Brasileira de Zootecnia, v.28, n.1, p.425-431, 1999. http://dx.doi.org/10.1590/S1516-35981999000200029

Serviço Brasileiro de Apoio às Micro e Pequenas Empresas - SEBRAE. Curso de capacitação rural. Goiânia: Sebrae, 1998. 34p.

Silva, H. A.; Koehler, H. S.; Moraes, A.; Guimarães, V. A.; Hack, E.; Carvalho, P. C. F. Análise da viabilidade econômica da produção de leite a pasto e com suplementos na região dos Campos Gerais - Paraná. Ciência Rural, v.38, n.2, p.445-450, 2008 . http://dx.doi.org/10.1590/S0103-84782008000200024 